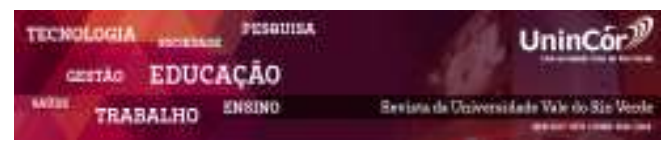

Revista da Universidade Vale do Rio Verde ISSN: 1517-0276 / EISSN: 2236-5362 v. 16 | n. 2 | Ano 2018

\section{A LEGISLAÇÃO E OS PLANOS DE RECURSOS HÍDRICOS NO BRASIL E EM MINAS GERAIS}

\section{RESUMO}

A elaboração dos Planos de Recursos Hídricos é crucial para a condução da gestão hídrica, por se tratar do principal instrumento de planejamento da política de recursos hídricos, seja para bacias federais ou estaduais, e deve atender as diretrizes determinadas pela legislação vigente. Objetiva-se com esse trabalho realizar o levantamento e a análise das legislações brasileiras e mineiras referentes ao processo de elaboração e conteúdo mínimo dos Planos de Recursos Hídricos e avaliar a sua atual conjuntura no Brasil e em Minas Gerais. A metodologia deste trabalho se baseia em revisão bibliográfica e análise crítica. A análise das legislações permitiu a identificação de 60 temas relacionados à diretrizes para o processo de elaboração e conteúdo mínimo dos Planos de Recursos Hídricos. A compatibilidade das legislações federais e estaduais foi comprovada pela similaridade das Políticas Nacional e Estadual de Recursos Hídricos, visto que dos 18 temas abordados pela lei estadual, 16 são recorrentes da lei federal. Verifica-se a importância da formulação e publicação das seis normas analisadas neste trabalho, dado que todas elas trouxeram novas diretrizes, sem desconsiderar aquelas já estabelecidas.

Palavras-chave: Plano de Recursos Hídricos. Política de Recursos Hídricos. Gestão de Recursos Hídricos. Legislação. Bacias Hidrográficas.

\section{LEGISLATION AND WATER RESOURCES PLANS IN BRAZIL AND MINAS GERAIS}

\begin{abstract}
The elaboration of Water Resources Plans is crucial for the conduct of water management, since it is the main planning instruments for water resources policy, whether for federal or state basins, and must comply with the directives determined by the current legislation. The objective of this work is to survey and analyze the legislation of Brazil and Minas Gerais regarding the process of preparation and minimum content of the Water Resources Plans and to evaluate its current situation in Brazil and Minas Gerais. The methodology of this work is based on bibliographic review and critical analysis. The analysis of legislation allowed the identification of 60 themes related to the drafting process and the minimum content of the Water Resources Plans. The compatibility of federal and state legislations was evidenced by the similarity of the National and State Policies of Water Resources, since of the 18 themes addressed by state law, 16 are recurrent of the federal law. It is verified the importance of formulation and publication of the six norms analyzed in this paper, since all of them have introduced new guidelines, without disregarding those already established.
\end{abstract}


Keywords: Water Resources Plan. Water Resources Policy. Management of Water Resources. Legislation. River Basin.

Recebido em: 05/03/2018 - Aprovado em: 04/11/2018 - Disponibilizado em: 15/12/2018

\section{INTRODUÇÂO}

Os instrumentos de gestão das Políticas Nacional e Estadual de Recursos Hídricos foram estabelecidos pela Lei Federal $n^{\circ} 9.433$, de 8 de janeiro de 1997 e Lei Estadual no 13.199 de 29 de janeiro de 1999, respectivamente, dentre eles: os Planos de Recursos Hídricos; o Enquadramento dos Corpos de Água em classes, segundo os usos preponderantes da água; a Outorga dos Direitos de Uso dos Recursos Hídricos; a Cobrança pelo Uso dos Recursos Hídricos; e o Sistema de Informações sobre Recursos Hídricos.

A implementação dos instrumentos de gestão ocorreu de forma gradativa e ainda representa uma barreira a ser vencida pelos Sistemas Nacional e Estadual de Gerenciamento dos Recursos Hídricos (IGAM, 2013). Contudo, o aprimoramento dos órgãos gestores e da sociedade participativa pela construção do conhecimento por meio da experiência prática ao longo dos anos de atuação na gestão de recursos hídricos têm apontado caminhos e possibilitado a construção de normas mais eficientes e maduras (MOTA, 2018).

Os Planos de Recursos Hídricos (PRH) orientam o gerenciamento dos recursos hídricos a curto, médio e longo prazo, visando garantir a qualidade e quantidade das águas para os usos múltiplos e fundamentar os tomadores de decisão, tomando as bacias hidrográficas como unidades de planejamento (IGAM, 2011). O processo de elaboração dos Planos de Recursos Hídricos ocorre com intensa participação da população local, favorecendo a efetividade e a adequação dos programas e ações propostas aos interesses da sociedade (SANTOS et al., 2018).

A elaboração dos Planos de Recursos Hídricos é crucial para a condução da gestão hídrica, por se tratar do principal instrumento de planejamento da política de Recursos Hídricos, seja para bacias federais ou estaduais, e deve atender as diretrizes determinadas pela legislação vigente, atentando-se para as normas estaduais estabelecidas pelos Conselhos Estaduais de Recursos Hídricos e pelos Comitês de Bacias Hidrográficas (IGAM, 2013).

Objetiva-se com esse trabalho realizar o levantamento e a análise das legislações brasileiras e mineiras referentes ao processo de elaboração e conteúdo mínimo dos Planos de Recursos Hídricos e avaliar a sua atual conjuntura no Brasil e em Minas Gerais.

\section{METODOLOGIA}

A metodologia deste trabalho se baseia em revisão bibliográfica e análise crítica e se divide em três etapas distintas:

1) Planos de Recursos Hídricos no Brasil: revisão do contexto histórico e da atual situação. 
2) Planos de Recursos Hídricos em Minas Gerais: revisão do contexto histórico e da atual situação.

3) Aspectos legais: revisão e análise crítica das legislações nacionais e mineiras que estabelecem os procedimentos de elaboração e o conteúdo mínimo dos Planos de Recursos Hídricos. A partir da revisão foi elaborado um quadro com os temas abordados pelas normas federais e estaduais, quando mencionados pela legislação em análise os seus respectivos campos de marcação foram sinalizados em azul ou cinza. A cor azul representa o pioneirismo em abordar determinado tema e a cor cinza a recorrência da abordagem em outra norma, considerando a ordem cronológica de elaboração das legislações. Os temas sinalizados em negrito foram tratados em quatro ou mais normas analisadas.

\section{RESULTADOS E DISCUSSÃO}

\subsection{Planos de Recursos Hídricos no Brasil}

O Plano Nacional de Recursos Hídricos (PNRH) do Brasil foi o primeiro plano de abrangência nacional das américas a ser elaborado e um dos poucos a cumprir o compromisso internacional assumido em conjunto com demais países integrantes do Sistema Nações Unidas durante a Cúpula de Joanesburgo (Rio +10), realizada em 2002 (SENRA e NASCIMENTO, 2017). Durante o encontro, os países participantes se comprometeram a elaborar seus planos de gestão integrada dos recursos hídricos e aproveitamento eficiente da água até 2005 (BRASIL, 2006).
O PNRH foi aprovado em 2006 pelo Conselho Nacional de Recursos Hídricos CNRH por meio da Resolução CNRH n ${ }^{\circ} 58$ de 30 de janeiro de 2006, com o objetivo geral de estabelecer um pacto nacional para a definição de diretrizes e políticas públicas, voltadas para a melhoria da oferta de água, em qualidade e quantidade, gerenciando as demandas e considerando ser a água um elemento estruturante para a implementação das políticas setoriais, sob a ótica do desenvolvimento sustentável e da inclusão social (ANA, 2013). Em seu escopo foram definidos ações e programas a serem implementadas até 2020 (MMA, 2006).

Atualmente, o Brasil possui 19 Planos Estaduais de Recursos Hídricos concluídos e elaborados em consonância com o PNRH para 18 estados e o Distrito Federal, conforme demonstrado pela Figura 1. Os PERH de quatro estados, Maranhão, Rondônia, Espírito Santo e Rio Grande do Sul, estão em elaboração. Amazonas, Amapá, Pará e Santa Catarina ainda não possuem PERH, mas já iniciaram as tratativas para providenciar a elaboração.

Em relação aos Planos de Recursos Hídricos que abrangem mais de uma bacia, em alguns casos podendo ultrapassar os limites estaduais, já foram elaborados treze dentro do território nacional (ANA, 2017), conforme a Figura 2. Dentre eles, sete englobam bacias localizados em Minas Gerais:

- Plano de Recursos Hídricos da Bacia Hidrográfica do Rio São Francisco;

- Plano de Recursos Hídricos da Bacia Hidrográfica do Rio Verde Grande; 
- $\quad$ Plano Integrado de Recursos Hídricos da Bacia Hidrográfica do Rio Doce;

- $\quad$ Plano Integrado de Recursos Hídricos da Bacia Hidrográfica do Rio Grande;

- Plano das Bacias Hidrográficas dos Rios

Piracicaba, Capivari e Jundiaí;
- Plano Integrado de Recursos Hídricos da Bacia Hidrográfica do Rio Paraíba do Sul; e

- Plano de Recursos Hídricos da Bacia Hidrográfica do Rio Paranaíba.

Figura 1 - Planos Estaduais de Recursos Hídricos em 2016.

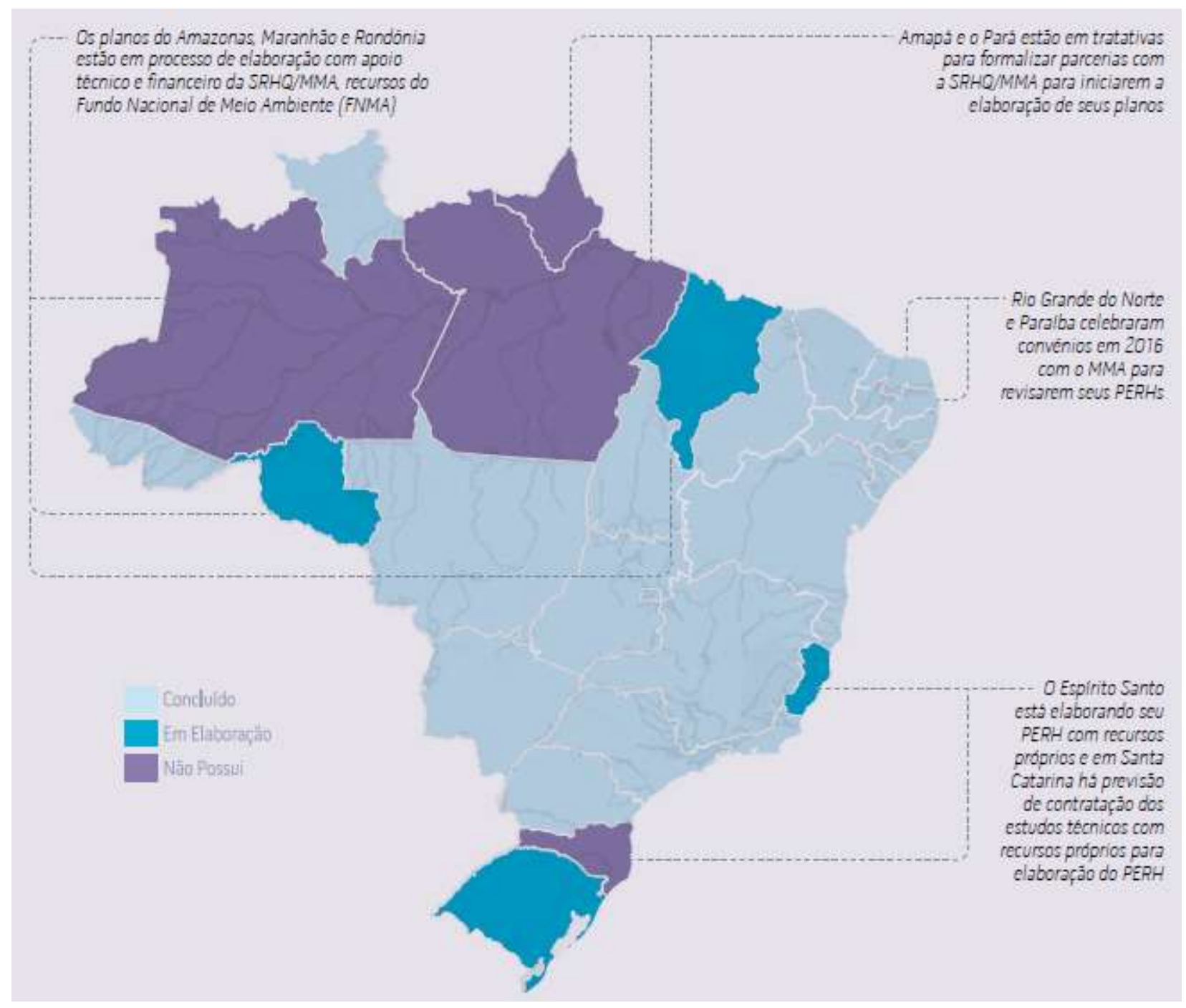

Fonte: ANA, 2017.

Segundo o Relatório Conjuntura dos Recursos Hídricos do Brasil 2017 (ANA, 2017), até o final de 2016 haviam sido elaborados 164 planos de bacias hidrográficas estaduais em 17 Unidades da Federação (UF) e 19 planos encontravam-se em elaboração em quatro estados (Espírito Santo, Bahia, Pernambuco e Paraná).
Conforme a Figura 3 que utiliza dados de 2016, São Paulo é a única Unidade Federativa do Brasil com $100 \%$ do seu território coberto por Planos Diretores de Recursos Hídricos. Minas Gerais está entre os seis estados com mais de 77\% de área contemplada por PDRH, com exatamente $87 \%$, atrás de São Paulo (100\%), 
Paraíba (91\%) e Rio de Janeiro (89\%) e na frente de Ceará (80\%) e Pernambuco (77\%). Porém, quando comparado em termos de área abrangida pelo instrumento, Minas Gerias possui o maior território do país com PDRH, cerca de 510.272 $\mathrm{km}^{2}$ de um total de $586.520 \mathrm{~km}^{2}$, enquanto São Paulo possui $248.219 \mathrm{~km}^{2}$ (MOTA, 2018; IBGE, 2017).

Figura 2 - Planos de Recursos Hídricos de bacias estaduais e interestaduais em 2016.

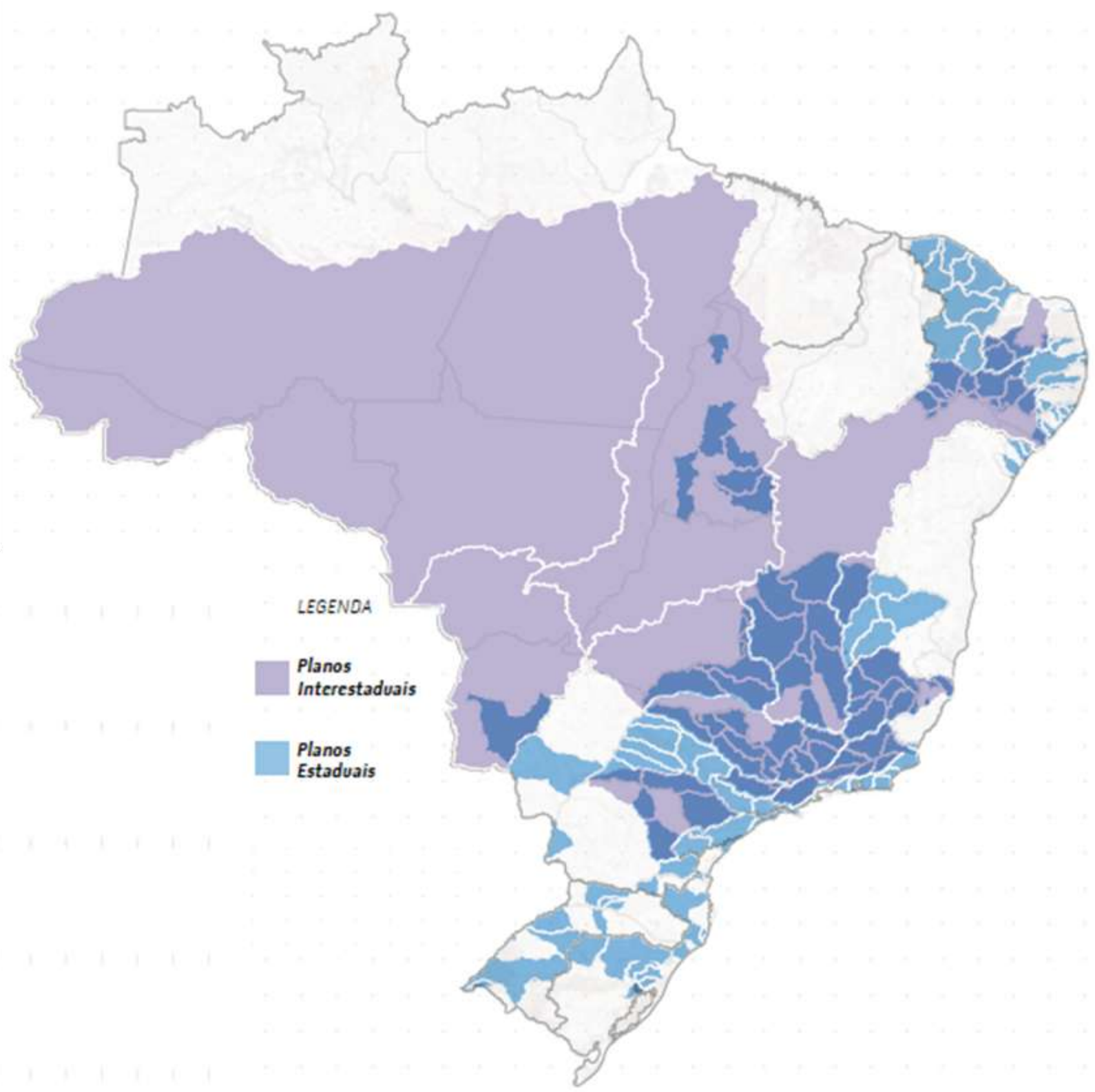

Fonte: Adaptado de ANA, 2017.

Com referência aos dados de 2018 de Minas Gerais, o Estado já possui $92 \%$ do seu território coberto por Planos Diretores de Recursos Hídricos, equivalente a cerca de $538.765 \mathrm{~km}^{2}$.
Além dos estados mencionados tem-se: Alagoas (54\%), Santa Catarina (44\%), Sergipe (43\%), Tocantins (35\%), Espírito Santo (33\%), Mato Grosso do Sul (25\%), Rio Grande do Sul (24\%), Paraná (10\%), Rio Grande do Norte (2\%) e Bahia (2\%) possuem Planos Diretores de 
Recursos Hídricos em algumas de suas bacias

PDRH (ANA, 2017).

hidrográficas. As demais UF ainda não têm

Figura 3 - Unidade Federativas com Planos Diretores de Recursos Hídricos em 2016.

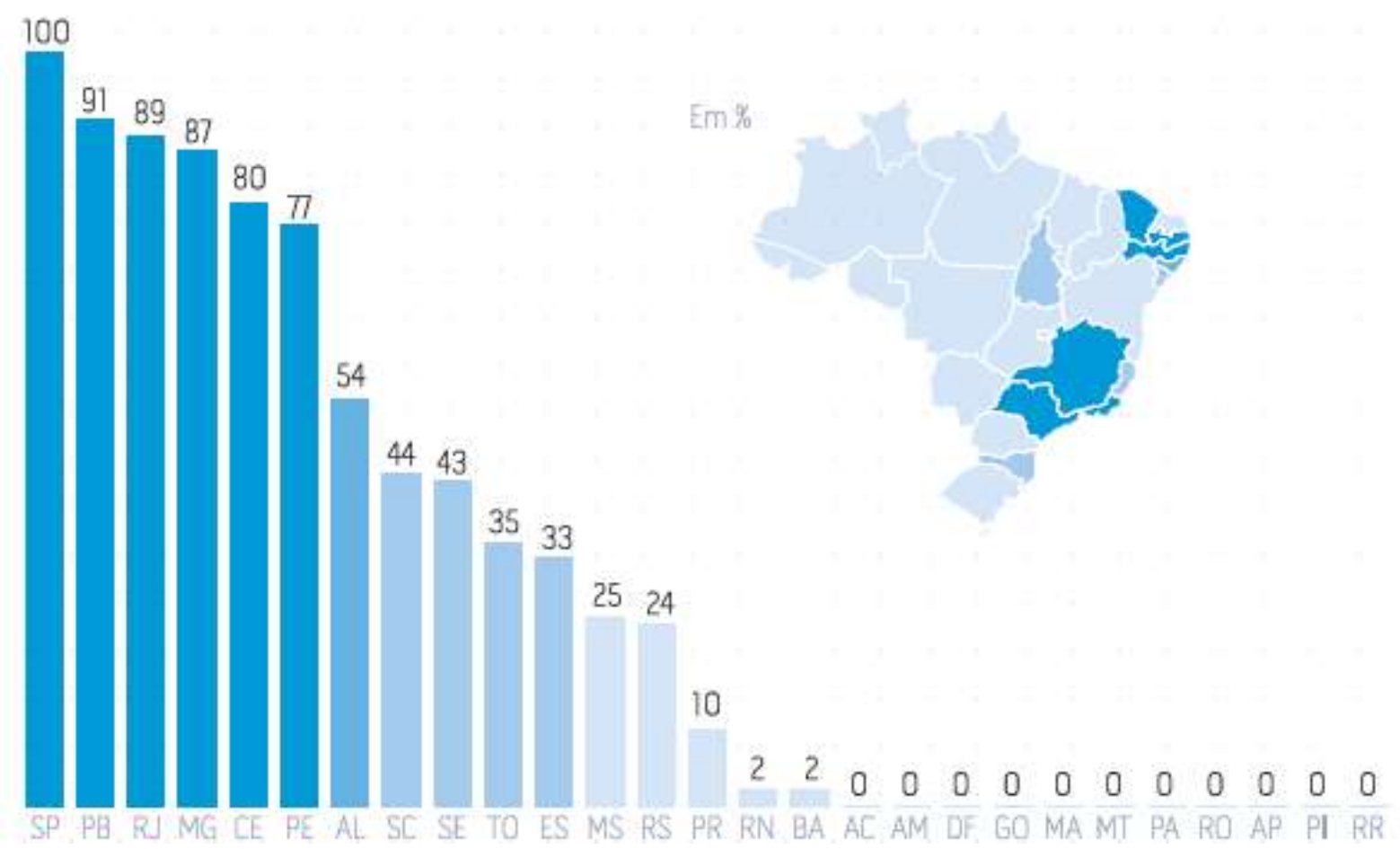

Fonte: ANA, 2017.

\subsection{Planos de Recursos Hídricos em Minas}

\section{Gerais}

Em Minas Gerais os Planos de Recursos Hídricos são elaborados em dois níveis conforme divisão apresentada na Figura 4 e nos tópicos abaixo (IGAM, 2013):

- Plano Estadual de Recursos Hídricos (PERH - MG) com abrangência estadual; e

- Planos Diretores de Recursos Hídricos (PDRH) por bacias hidrográficas.

A elaboração do Plano Estadual de Recursos Hídricos de Minas Gerais iniciou-se em 2006 e foi concluído em 2010, sendo aprovado pelo Conselho Estadual de Recursos
Hídricos de Minas Gerais por meio da Deliberação CERH/MG no 260, de 26 de novembro de 2010. O Governo de Minas também aprovou o PERH - MG no ano seguinte por meio do Decreto $n^{\circ} 45.565$, de 22 de março de 2011 (IGAM, 2013).

Segundo IGAM (2018), atualmente o estado de Minas Gerais possui 30 PDRH concluídos entre 2006 e 2018, abrangendo 30 Unidades de Planejamento de Gestão de Recursos Hídricos - UPGRH de um total de 36. Conforme demonstrado na Figura 5, dentre as seis UPGRH que ainda não possuem PDRH, cinco estão em fase de elaboração (rio Paraopeba - SF3, rio São Mateus - SM, rio Mucuri - MU, Afluentes do Médio rio Grande - GD7 e Afluentes do Baixo rio Grande - GD8) e uma 
está em fase de contratação de empresa de do PDRH (Alto São Francisco - SF1).

consultoria técnica especializada para elaboração

Figura 4 - Níveis de elaboração dos Planos de Recursos Hídricos de Minas Gerais.

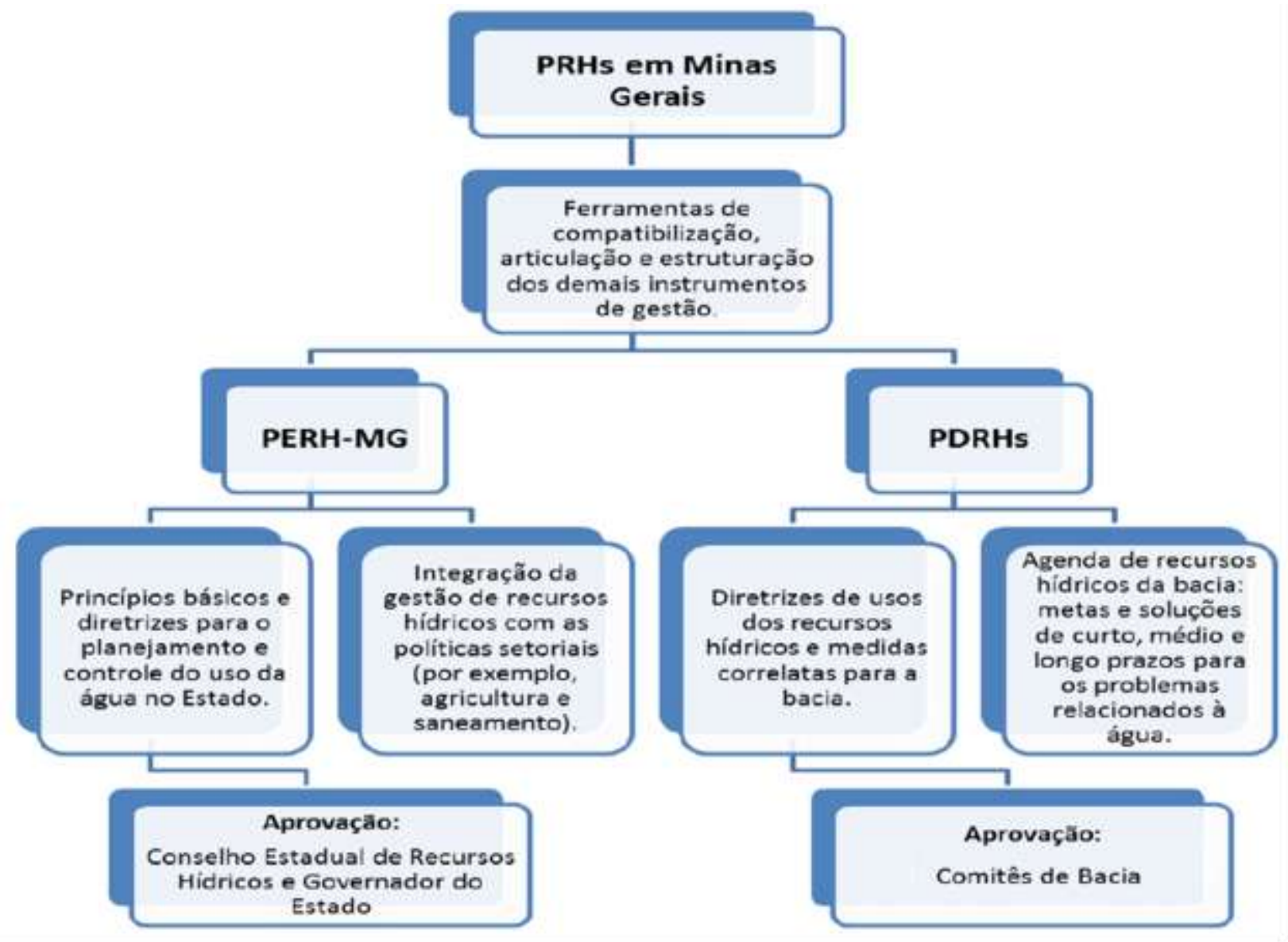

Fonte: Adaptado de IGAM, 2013.

As bacias hidrográficas do Rio Buranhém, do Rio Jucuruçu, do Rio Itanhém (Alcobaça), do Rio Peruípe, do Rio Itaúnas, do Rio Itapemirim e do Rio Itabapoana no leste do estado não são consideradas Unidades de Planejamento e Gestão de Recursos Hídricos. Porém, está em andamento a elaboração de um Plano Diretor de Recursos Hídricos que engloba todas essas bacias e serão elaborados cadernos de Planos de Ações específicos para cada uma delas.

Cabral (2015) realizou uma análise dos instrumentos da Política Nacional de Recursos Hídricos em Minas Gerais e concluiu que os mesmos possuem alta contribuição para a gestão adequada dos recursos hídricos no estado, principalmente devido ao grande número de Planos Diretores de Recursos Hídricos já elaborados para as suas bacias hidrográficas.

Considerando o Plano Estadual de Recursos Hídricos e os 30 Planos Diretores de Recursos Hídricos de Minas Gerais já finalizados, estão disponíveis enquanto instrumento de planejamento da gestão $\mathbf{2 2 0}$ Componentes, 381 Programas e 955 Ações que visam melhorar a quantidade e a qualidade das águas do Estado. 
Figura 5 - Situação dos Planos Diretores de Recursos Hídricos de Minas Gerais em 2018.

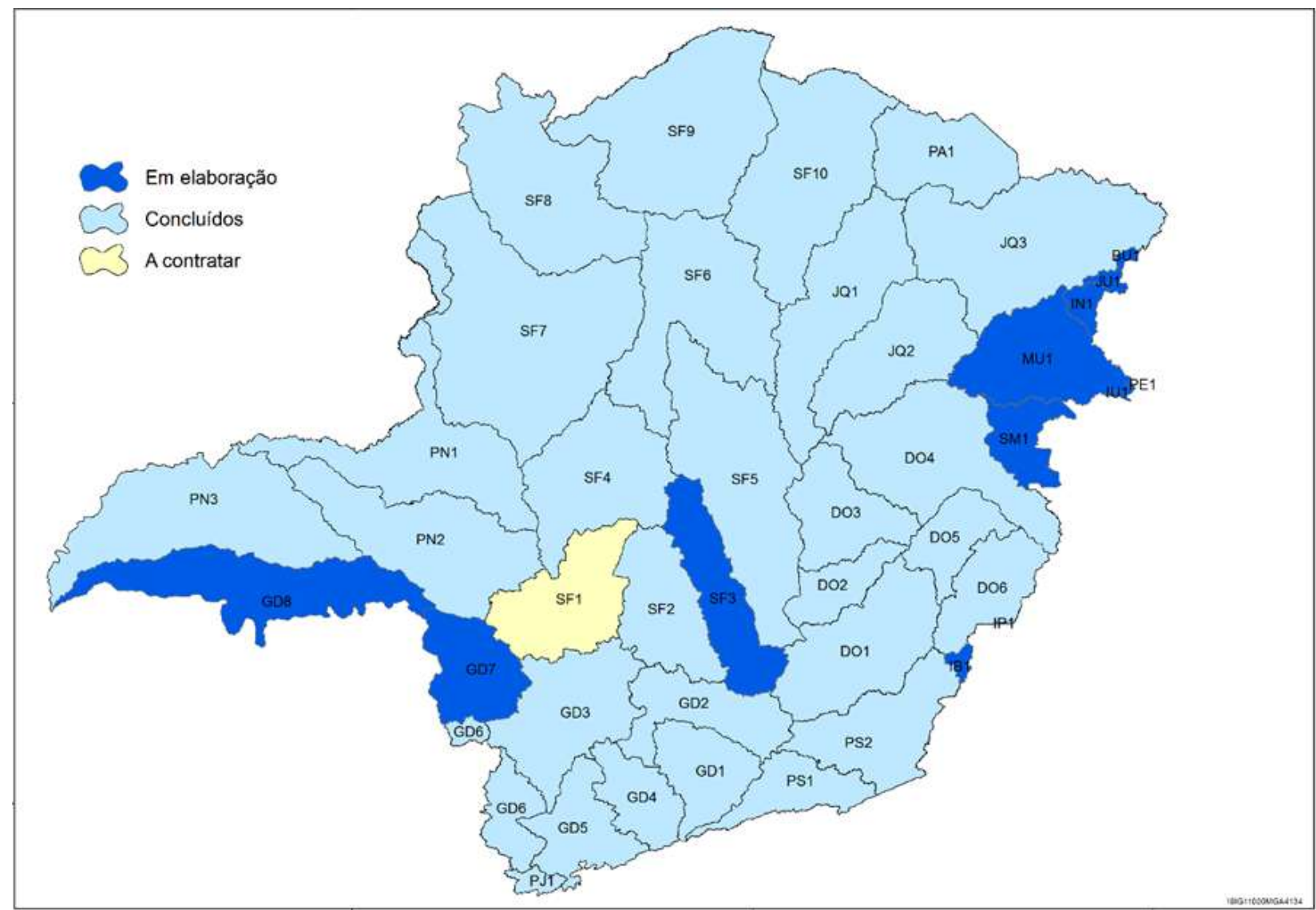

Fonte: IGAM, 2018.

\subsection{Aspectos Legais}

Os Planos de Recursos Hídricos (PRH) visam fundamentar e nortear a implementação das Políticas Nacional e Estadual de Recursos Hídricos e o gerenciamento dos mesmos, a curto, médio e longo prazo, com horizonte de planejamento compatível com o período de implantação de seus programas e projetos, devendo ser acompanhados de revisões periódicas (IGAM, 2013; GRABHER et al., 2010).

O planejamento da gestão das águas é essencial para definir as melhores alternativas de utilização dos recursos, buscar o uso racional, garantir o acesso ao recurso hídrico em quantidade e qualidade para todos e orientar a tomada de decisão, de modo a produzir os melhores resultados econômicos, sociais e ambientais (ANA, 2012a; 2012b; IGAM, 2011).

A Figura 6 apresenta a ordem cronológica da evolução das legislações federais e estaduais que estabelecem os procedimentos e conteúdo mínimo dos Planos de Recursos Hídricos.

Conforme observado na Figura 6, a primeira lei brasileira com diretrizes para os PRH foi publicada em 1997 e instituiu a Política Nacional de Recursos Hídricos - PNRH (Lei Federal $n^{\circ}$ 9.433/1997). Ao longo dos 22 anos que se seguiram, outras 5 legislações com orientações relacionadas aos Planos de Recursos Hídricos foram publicadas, quatro estaduais e uma federal. 
No entanto, nota-se um intervalo de 16 anos entre as publicações da PNRH, em janeiro de 1997, e da Resolução do Conselho Nacional de Recursos Hídricos $n^{\circ}$ 145, em dezembro de 2012, estabelecendo as diretrizes para a elaboração dos Planos de Recursos Hídricos. Durante esse período, Minas Gerais instituiu (Lei
Estadual $\left.\mathrm{n}^{\mathrm{o}} \quad 13.199 / 1999\right)$ e regulamentou (Decreto Estadual n ${ }^{\circ} 41.578 / 2001$ ) a Política Estadual de Recursos Hídricos e publicou o Decreto Estadual $\mathrm{n}^{\mathrm{o}}$ 44.046/2005, regulamentando a cobrança pelo uso de recursos hídricos de domínio do Estado.

Figura 6 - Evolução das legislações federais e estaduais referentes a Planos de Recursos Hídricos.

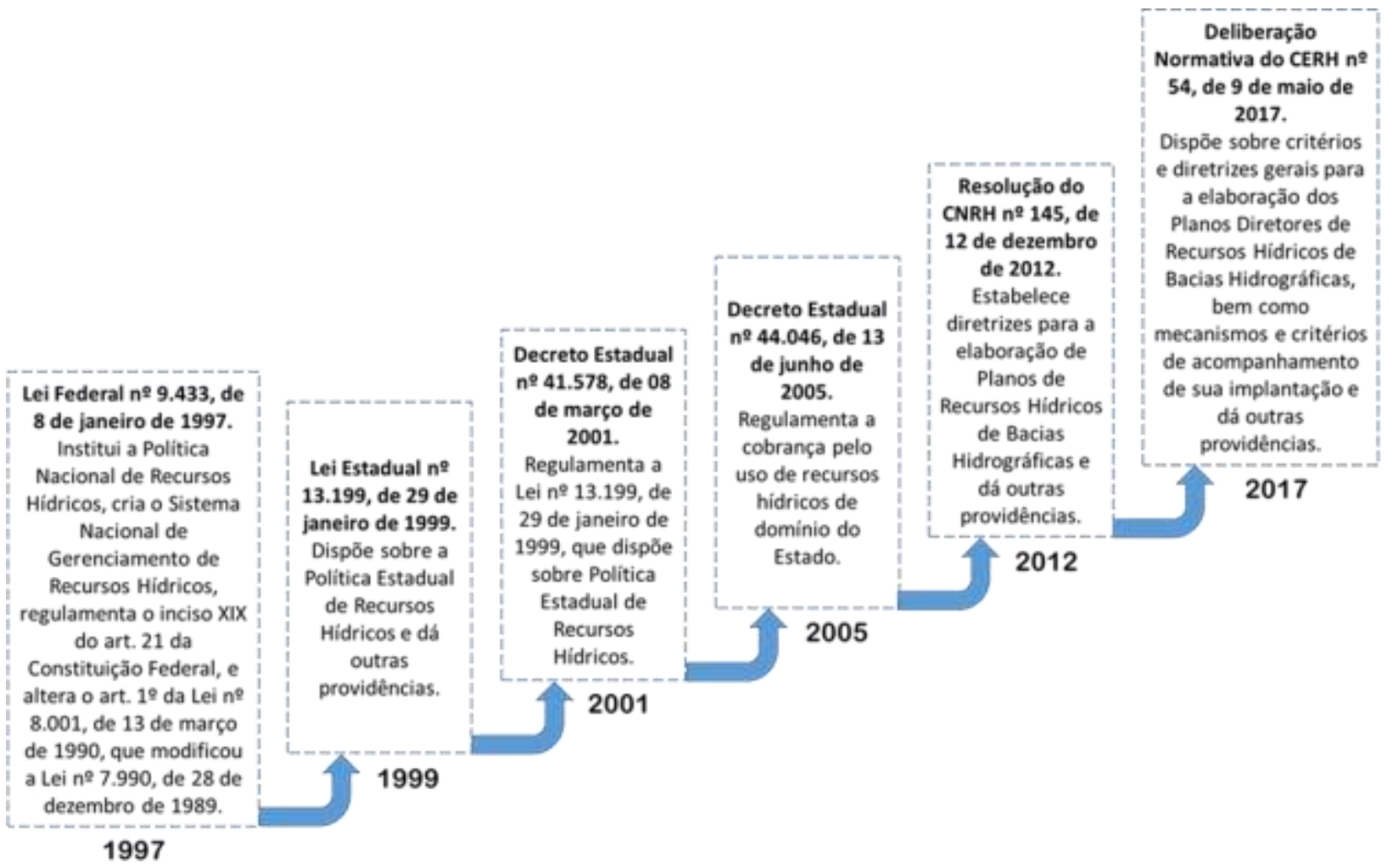

Em 2017, o Conselho Estadual de Recursos Hídricos de Minas Gerais publicou a Deliberação Normativa $n^{\circ} \quad 54 / 2017$, estabelecendo critérios e diretrizes para a elaboração dos Planos Diretores de Recursos Hídricos e mecanismos para o acompanhamento da sua implementação. A referida deliberação é a norma mais recente sobre o assunto, com pouco mais de um ano de vigência e procurou complementar a legislação federal (Resolução CNRH nº 145/2012), já há quase seis anos em vigor. Os mecanismos estabelecidos chegam em

boa hora, visto que, conforme observado na Figura 5, mais de $80 \%$ das Unidades de Planejamento e Gestão de Recursos Hídricos do Estado já possuem PDRH e precisam acompanhar as suas implementações.

O Quadro 1 apresenta os temas abordados pelas seis legislações vigentes com diretrizes para a elaboração e conteúdo mínimo dos Planos de Recursos Hídricos. A cor azul representa o pioneirismo em abordar determinado tema e a cor cinza a recorrência da abordagem em outra norma, considerando a 
ordem cronológica de elaboração das legislações.

em quatro ou mais normas analisadas.

Os temas sinalizados em negrito foram tratados

QUADRO 1 - Temas abordados pelas legislações federais e estaduais com diretrizes para a elaboração e conteúdo mínimo dos Planos de Recursos Hídricos.

\begin{tabular}{|c|c|c|c|c|c|c|}
\hline & FEDERAL & \multicolumn{3}{|c|}{ ESTADUAL } & \multirow{2}{*}{$\begin{array}{c}\text { FEDERAL } \\
\text { Resolução } \\
\text { do CNRH } \\
\text { no } \\
145 / 2012\end{array}$} & \multirow{2}{*}{$\begin{array}{c}\text { ESTADUAL } \\
\text { Deliberação } \\
\text { Normativa } \\
\text { do CERH-MG } \\
\text { no 54/2017 }\end{array}$} \\
\hline & $\begin{array}{l}\text { Lei Federal } \\
\text { no } \\
9.433 / 1997\end{array}$ & $\begin{array}{l}\text { Lei Estadual } \\
\quad \text { no } \\
13.199 / 1999\end{array}$ & $\begin{array}{l}\text { Decreto } \\
\text { Estadual no } \\
41.578 / 2001\end{array}$ & $\begin{array}{c}\text { Decreto } \\
\text { Estadual no } \\
44.046 / 2005\end{array}$ & & \\
\hline \multicolumn{7}{|l|}{$\begin{array}{l}\text { Bacia Hidrográfica como unidade } \\
\text { de gestão de recursos hídricos }\end{array}$} \\
\hline \multicolumn{7}{|l|}{ PRH como instrumento de gestão } \\
\hline \multicolumn{7}{|l|}{$\begin{array}{l}\text { PERH como instrumento de gestão } \\
\text { participativa, descentralizada e de } \\
\text { integração entre os órgãos e } \\
\text { entidades do SEGRH-MG }\end{array}$} \\
\hline \multicolumn{7}{|l|}{$\begin{array}{l}\text { Entes responsáveis pela } \\
\text { elaboração e aprovação dos PRH }\end{array}$} \\
\hline \multicolumn{7}{|l|}{$\begin{array}{l}\text { Participação da sociedade: } \\
\text { consultas públicas, encontros } \\
\text { técnicos, oficinas de trabalho ou } \\
\text { por quaisquer outros meios de } \\
\text { comunicação }\end{array}$} \\
\hline \multicolumn{7}{|l|}{$\begin{array}{l}\text { Diagnóstico da situação dos } \\
\text { recursos hídricos }\end{array}$} \\
\hline \multicolumn{7}{|l|}{$\begin{array}{l}\text { Três etapas: Diagnóstico, } \\
\text { Prognóstico e Plano de Ações }\end{array}$} \\
\hline \multicolumn{7}{|l|}{ Componentes, programas e ações } \\
\hline \multicolumn{7}{|l|}{$\begin{array}{c}\text { Ações organizadas em } \\
\text { componentes, programas e } \\
\text { subprogramas, com justificativa, } \\
\text { objetivos, executor, investimentos, } \\
\text { fontes possíveis de recursos, prazo } \\
\text { de implantação }\end{array}$} \\
\hline \multicolumn{7}{|l|}{$\begin{array}{c}\text { Recomendações de ordem } \\
\text { operacional para a implementação } \\
\text { do plano }\end{array}$} \\
\hline \multicolumn{7}{|l|}{$\begin{array}{l}\text { Metas de curto, médio e longo } \\
\text { prazos }\end{array}$} \\
\hline \multicolumn{7}{|l|}{ Utilização de dados secundários } \\
\hline \multicolumn{7}{|l|}{ Resumo Executivo } \\
\hline \multicolumn{7}{|l|}{ Áreas Sujeitas à Restrição de Uso } \\
\hline \multicolumn{7}{|l|}{$\begin{array}{l}\text { Indicadores de implementação das } \\
\text { ações }\end{array}$} \\
\hline $\begin{array}{l}\text { Diretrizes para implementação } \\
\text { dos demais instrumentos de } \\
\text { gestão }\end{array}$ & & & & & & \\
\hline
\end{tabular}




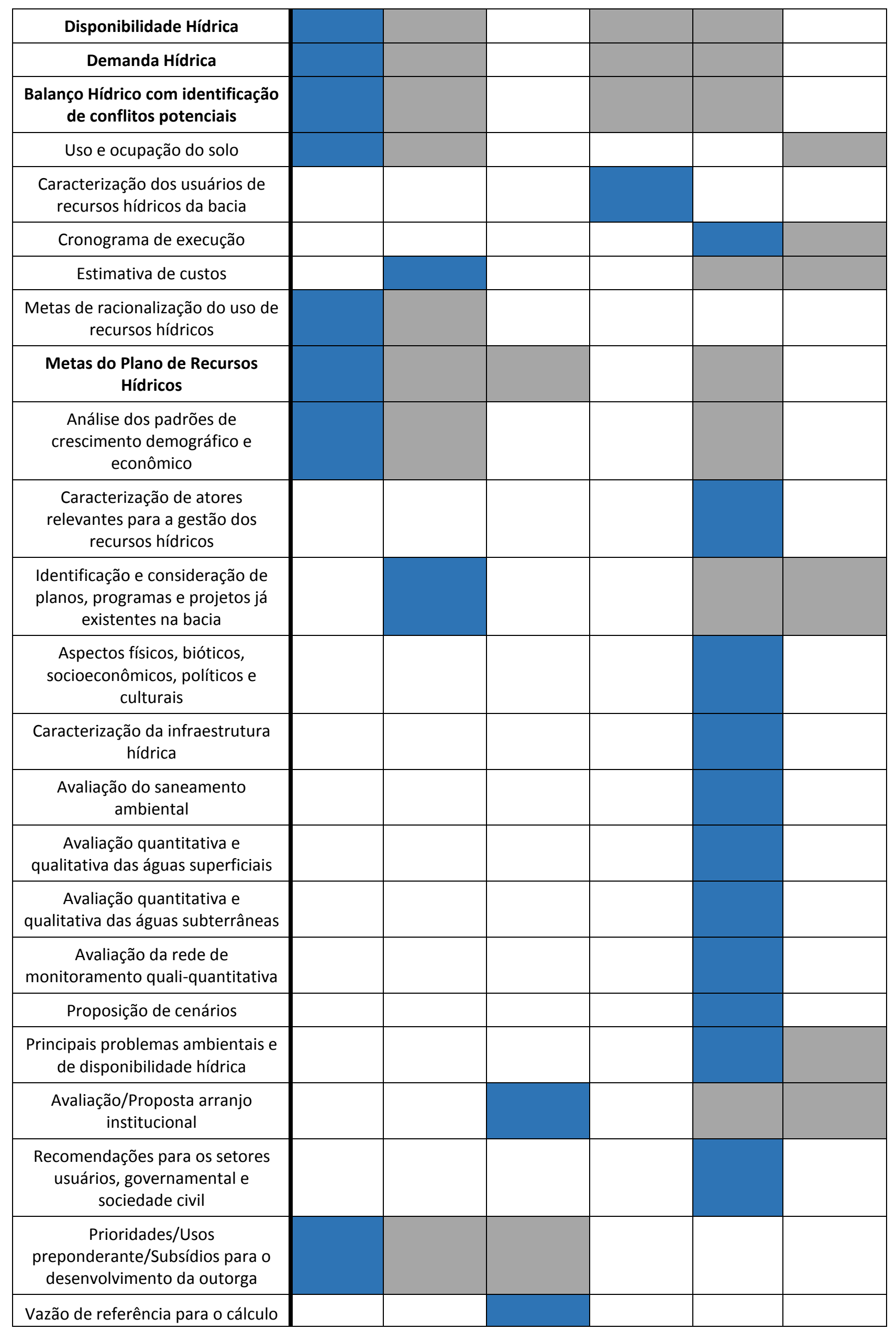




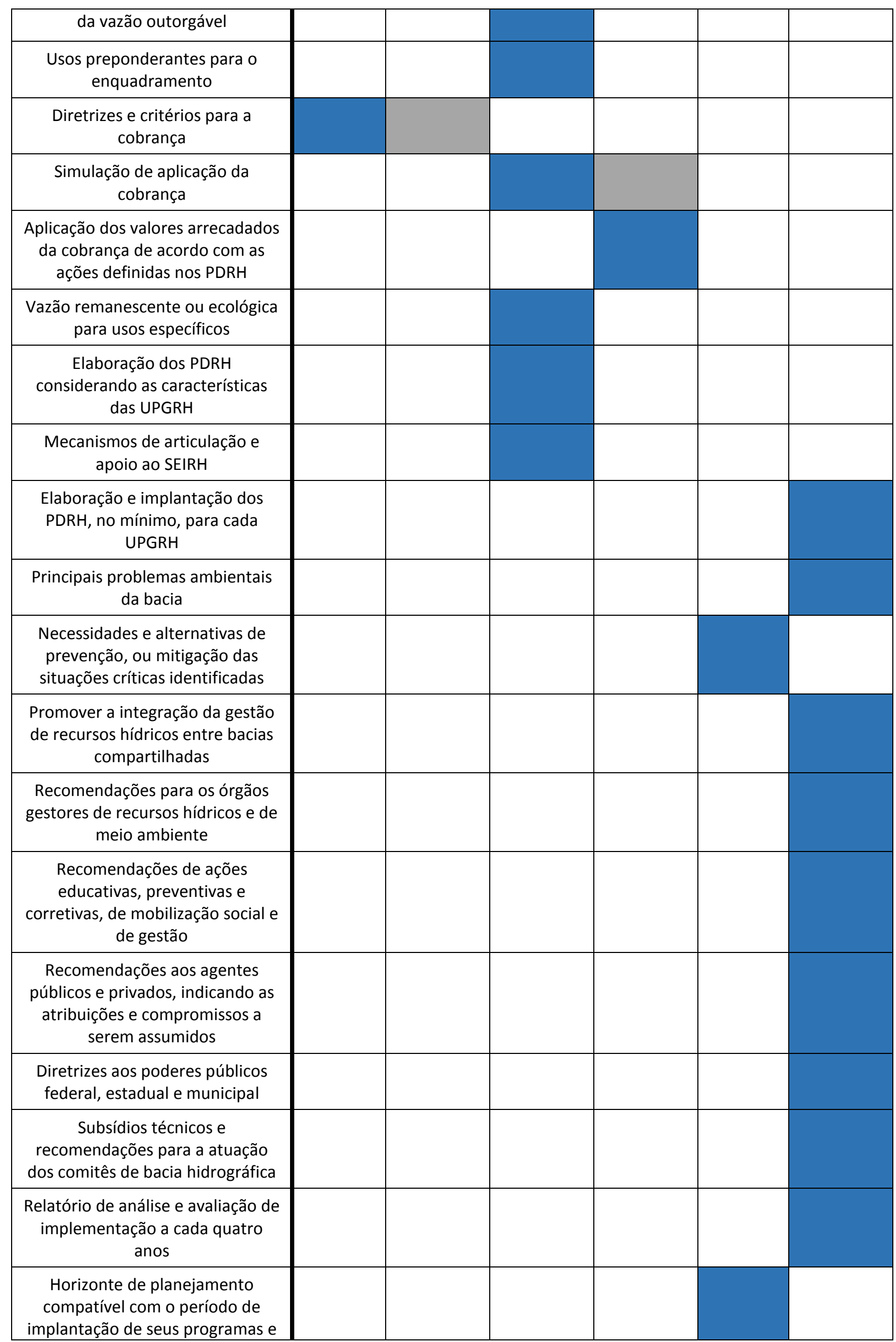




\begin{tabular}{|c|c|c|c|c|c|c|c|}
\hline \multicolumn{8}{|c|}{ projetos } \\
\hline \multicolumn{8}{|c|}{$\begin{array}{l}\text { Horizonte de planejamento } \\
\text { mínimo de } 20 \text { anos }\end{array}$} \\
\hline \multicolumn{8}{|c|}{$\begin{array}{c}\text { Equiparação dos PARH } \\
\text { desenvolvidos até } 09 / 05 / 17 \text { à } \\
\text { PDRH }\end{array}$} \\
\hline TOTAL & 60 & 16 & 18 & 14 & 7 & 35 & 23 \\
\hline \multicolumn{2}{|c|}{$\begin{array}{l}\text { TOTAL DE TEMAS ABORDADOS } \\
\text { PELA 1므 VEZ NA LEGISLAÇÃOO }\end{array}$} & 16 & 2 & 8 & 2 & 20 & 12 \\
\hline
\end{tabular}

De acordo com o Quadro 1, foram identificados 60 temas relacionados à diretrizes para o processo de elaboração e conteúdo mínimo dos Planos de Recursos Hídricos, dos quais 35 foram abordados pela Resolução CNRH $n^{\circ} 145 / 2012$, norma com o maior número de temas tratados. O grande número de temas abordados se deve ao fato da legislação em questão ser a primeira do Brasil específica para estabelecer diretrizes para a elaboração dos PRH e a primeira a subdividi-los em três etapas (Diagnóstico, Prognóstico e Plano de Ações), definindo o conteúdo mínimo para cada uma delas. A Resolução do Conselho Nacional de Recursos Hídricos também apresentou o maior número de temas abordados pela primeira vez na legislação brasileira, 20, no total, certamente pelos mesmos motivos mencionados anteriormente.

Em seguida, com maior número de temas abordados, em ordem decrescente, encontram-se a Deliberação Normativa CERH $n^{\circ} 54 / 2017$, a Lei Estadual $n^{\circ} 13.199 / 1999$, Lei Federal $n^{\circ}$ 9.433/1997, o Decreto Estadual n ${ }^{\circ} 41.578 / 2001$ e o Decreto Estadual no 44.046/2005, com 23, 18, 16, 14 e 7 temas abordados, respectivamente. Similarmente à análise anterior da Resolução CNRH $n^{\circ} 145 / 2012$, a Deliberação Normativa
CERH no 54/2017 é a primeira legislação mineira específica para estabelecer diretrizes para a elaboração dos PRH, motivo pelo qual alcançou o segundo lugar em número de temas abordados.

As leis que estabeleceram a Política Estadual de Recursos Hídricos de Minas Gerais e a Política Nacional de Recursos Hídricos e o Decreto Estadual no 41.578/2001 não apresentaram os números mais altos de temas abordados, mas ainda assim trataram sobre vários deles ao definir os Planos de Recursos Hídricos como instrumentos de gestão das suas políticas, 18, 16 e 14 temas, respectivamente.

O Decreto Estadual $\mathrm{n}^{\circ} 44.046 / 2005$ abordou apenas 7 temas, 2 deles de forma pioneira, devido ao seu objetivo não ser específico para a elaboração dos $\mathrm{PRH}$, mas de regulamentar a cobrança pelo uso de recursos hídricos de domínio do Estado, apontando diretrizes importantes sobre o instrumento que devem constar nos Planos Diretores de Recursos Hídricos.

Embora a Deliberação Normativa CERH $\mathrm{n}^{\mathrm{o}} 54 / 2017$ tenha abordado mais temas quando comparado ao número de temas abordados pela Lei Federal no 9.433/1997, esta última à supera no número de temas abordados de modo 
pioneiro, claramente por ter sido a primeira legislação brasileira a tratar do processo de elaboração de PRH ao instituir a Política Nacional de Recursos Hídricos.

Dentre as informações obtidas, é motivo de destaque a similaridade das Políticas Nacional e Estadual de Recursos Hídricos, visto que dos 18 temas abordados pela lei estadual, 16 são recorrentes da lei federal, caracterizando a compatibilidade das legislações. Existem apenas dois temas tratados de forma pioneira, a apresentação da estimativa de custos das ações previstas e a diretriz de identificação e consideração de planos, programas e projetos existentes na bacia para a elaboração do PDRH. O pioneirismo é aumentado no momento da regulamentação da Política Estadual de Recursos Hídricos, quando o Decreto Estadual $\mathrm{n}^{\circ}$ 41.578/2001 apresenta 8 temas novos.

Verifica-se a importância da formulação e publicação das seis normas analisadas neste trabalho, dado que todas elas trouxeram novas diretrizes, sem desconsiderar aquelas já estabelecidas. No total, 37 temas apareceram apenas uma vez, representando mais de $60 \%$ dos temas trabalhados, o que demonstra a capacidade de complementação das legislações, estabelecendo novas diretrizes para preencher lacunas existentes e padronizar procedimentos.

É possível apontar como exemplo de complementação das legislações, os temas que tratam do acompanhamento da implementação dos Planos de Recursos Hídricos. A Resolução CNRH n ${ }^{\circ}$ 145/2012 define que o Plano de Ações deve possuir indicadores que permitam avaliar o nível de implementação das ações propostas e a Deliberação Normativa CERH $n^{\circ} \quad 54 / 2017$ estabelece que as Agências de Bacias ou Entidades a Elas Equiparadas, e na sua ausência o Órgão Gestor, deverão publicar, a cada quatro anos, relatório de análise e avaliação de implementação dos Planos Diretores de Recursos Hídricos.

Vale destacar que as duas diretrizes visam dotar os tomadores de decisão de uma ferramenta importante para a condução dos trabalhos: o conhecimento da situação de implementação dos PRH. A utilização de indicadores por gestores de entidades públicas e privadas têm se tornado cada vez mais comum, fornecendo dados bem próximos da realidade sobre o processo ou a atividade que se deseja acompanhar, possibilitando a elaboração de relatórios periódicos de implementação ou execução. Segundo Campos \& Melo (2008), é imprescindível a existência de um sistema de medidas que assegure o alinhamento das atividades com o objetivo maior da organização. Assim, a qualidade da tomada de decisão e os custos empregados serão otimizados para cada ação prevista no plano de trabalho ou programa.

Não era usual até o ano de 2017 balizar, na prática, a execução das diretrizes e ações dos PRH por meio de indicadores, mesmo que já houvesse essa intenção. É possível que o grande entrave para este tema fosse a carência de uma metodologia com capacidade adaptável para se ajustar as peculiaridades de cada PDRH. No entanto, em consonância com esta demanda, foi proposto por MOTA (2018) um método capaz de avaliar o grau de implementação das ações dos PRH e a capacidade de suporte das Unidades de Planejamento e Gestão de Recursos Hídricos por meio de indicadores, além de sistematizar os 
dados em matrizes de avaliação. Os resultados são aplicados e divulgados utilizando-se o relatório de análise do Índice de Implementação dos Planos de Ações - IPA e do Índice de Suporte à Gestão - ISG.

O relatório periódico do dispositivo legal tem relação direta com o desenvolvimento de indicadores de avaliação da implementação dos planos, bem como outros indicadores finalísticos, propiciando, assim, conduzir e acompanhar a execução do planejamento das ações dos PRH, apresentando com detalhes a situação de implementação do plano, os desvios da execução e os acertos ao longo dos anos. A utilização de ferramentas de avaliação, acompanhamento e controle é a chave para o gerenciamento dos recursos hídricos.

Referente ao estabelecimento de novas diretrizes para preencher lacunas existentes, vale apontar como exemplo o tema "Equiparação dos PARH desenvolvidos até 09/05/17 à PDRH”, da legislação mineira mais recente sobre Planos Diretores de Recursos Hídricos. A Agência Nacional de Águas (ANA) conduziu a elaboração de uma série de Planos Integrados de Recursos Hídricos que abordam um conjunto de bacias e para cada bacia componente foi elaborado um caderno específico com as suas peculiaridades: o Plano de Ação de Recursos Hídricos. No entanto, até a publicação da Deliberação Normativa CERH $n^{\circ}$ 54/2017, nenhuma legislação havia mencionado a possibilidade ou a legalidade da elaboração dos PARH em consonância com os PIRH, permanecendo a incerteza se os mesmos poderiam ser considerados equivalentes aos Planos Diretores de Recursos Hídricos.
Após a publicação da DN CERH $n^{\circ}$ 54/2017, foi possível aprovar os PARH nos Comitês afluentes e considerá-los formalmente como PDRH. Tal alteração normativa possui influência direta nos demais instrumentos de gestão, visto que o PDRH possui diretrizes para a sua implementação e que a cobrança pelo uso dos recursos hídricos em concomitância com a Agência de Bacia ou entidade equiparada só pode ser iniciada quando a bacia hidrográfica possuir o Plano Diretor de Recursos Hídricos concluído e aprovado.

Os outros 23 temas expostos pelas legislações em questão foram recorrentes pelo menos uma vez, consolidando-os como diretrizes fundamentais durante a elaboração dos Planos de Recursos Hídricos, com ênfase aos nove que foram recorrentes por pelo menos quatro vezes.

Ao analisar os temas com maior recorrência, nota-se a relevância dos mesmos, como a definição dos PRH como instrumentos de gestão das Políticas Nacional e Estadual de Recursos Hídricos, a indicação dos entes responsáveis pela sua elaboração e aprovação e a determinação de conteúdos importantes para as suas três subdivisões: o Diagnóstico e o Prognóstico devem tratar das áreas sujeitas à restrição de uso, apresentar a disponibilidade, a demanda e o balanço hídrico com a identificação de conflitos potenciais e o Plano de Ações deve conter as metas do PRH e os componentes, programas e ações para alcançá-las e as diretrizes para implementação dos demais instrumentos de gestão. 


\section{CONCLUSÕES}

O Brasil foi o primeiro país das américas a elaborar o Plano Nacional de Recursos Hídricos em 2006 e hoje possui 19 Planos Estaduais de Recursos Hídricos e 13 Planos Integrados de Recursos Hídricos, sendo que sete destes englobam bacias hidrográficas mineiras.

Minas Gerias concluiu o Plano Estadual de Recursos Hídricos em 2010 e atualmente possui 30 Planos Diretores de Recursos Hídricos concluídos, totalizando 220 componentes, 381 programas e 955 ações. Outros seis PDRH estão em elaboração e um em fase de contratação.

Desde 1997, foram publicadas seis legislações com referências ao processo de elaboração e conteúdo mínimo dos Planos de Recursos Hídricos, sendo duas federais e quatro estaduais. A Resolução CNRH n ${ }^{\circ}$ 145/2012 e a Deliberação Normativa CERH n ${ }^{\circ}$ 54/2017 são as únicas normas específicas para o estabelecimento de diretrizes para a elaboração de Planos de Recursos Hídricos de Bacias Hidrográficas.

A análise das legislações permitiu a identificação de 60 temas relacionados à diretrizes para o processo de elaboração e conteúdo mínimo dos Planos de Recursos Hídricos. A Resolução CNRH n ${ }^{\circ}$ 145/2012, norma com o maior número de temas tratados e o maior número de temas abordados pela primeira vez na legislação brasileira, alcançou essa marca por ser a primeira norma brasileira específica para estabelecer diretrizes para a elaboração dos PRH e a primeira a subdividi-los em três etapas (Diagnóstico, Prognóstico e Plano de Ações), definindo o conteúdo mínimo para cada uma delas.

A compatibilidade das legislações federais e estaduais foi comprovada pela similaridade das Políticas Nacional e Estadual de Recursos Hídricos, visto que dos 18 temas abordados pela lei estadual, 16 são recorrentes da lei federal.

Verifica-se a importância da formulação e publicação das seis normas analisadas neste trabalho, dado que todas elas trouxeram novas diretrizes, sem desconsiderar aquelas já estabelecidas. No total, 37 temas apareceram apenas uma vez, representando mais de $60 \%$ dos temas trabalhados, o que demonstra a capacidade de complementação das legislações, estabelecendo novas diretrizes para preencher lacunas existentes e padronizar procedimentos. Os outros 23 temas expostos pelas legislações em questão foram recorrentes pelo menos uma vez, consolidando-os como diretrizes fundamentais durante a elaboração dos Planos de Recursos Hídricos, com ênfase aos nove que foram recorrentes por pelo menos quatro vezes.

\section{REFERÊNCIAS}

AGÊNCIA NACIONAL DE ÁGUAS - ANA. Conjuntura dos recursos hídricos no Brasil: informe 2012. Ed. Especial. Brasília: Agência Nacional de Águas, 215 p, 2012a.

AGÊNCIA NACIONAL DE ÁGUAS - ANA. Conjuntura dos recursos hídricos no Brasil 2017: Relatório Pleno. Brasília: Agência Nacional de Águas, 169 p, 2017.

AGÊNCIA NACIONAL DE ÁGUAS - ANA. Panorama da qualidade das águas superficiais do Brasil: 2012. Brasília: Agência Nacional de Águas, 264 p, 2012b. 
AGÊNCIA NACIONAL DE ÁGUAS - ANA. Planos de recursos hídricos e enquadramento dos corpos de água. Brasília: Agência Nacional de Águas, 2013, 68 p.

AGÊNCIA NACIONAL DE ÁGUAS. Plano

Integrado de Recursos Hídricos da Bacia Hidrográfica do Rio Grande - PIRH-Grande. Resumo Executivo, 2018, 95p.

AGÊNCIA NACIONAL DE ÁGUAS. Plano de Ação de Recursos Hídricos da Unidade de Planejamento e Gestão de Recursos Hídricos Baixo Grande. PARH, 2018, 326p.

AGÊNCIA NACIONAL DE ÁGUAS. Plano de Ação de Recursos Hídricos da Unidade de Planejamento e Gestão de Recursos Hídricos Médio Grande. PARH, 2018, 316p.

BRASIL. Leis e Decretos. Lei Federal n ${ }^{\circ}$ 9.433, de 08 de janeiro de 1997. Institui a Política Nacional de Recursos Hídricos, cria o Sistema Nacional de Gerenciamento de Recursos Hídricos, regulamenta o inciso XIX do art. 21 da Constituição Federal, e altera o art. $1^{\circ}$ da Lei $\mathrm{n}^{\circ} 8.001$, de 13 de março de 1990, que modificou a Lei $n^{\circ} 7.990$, de 28 de dezembro de 1989. Brasil, Brasília, 08 de janeiro de 1997.

BRASIL. Plano nacional de recursos hídricos: panorama e estado dos recursos hídricos do Brasil. Brasília: Ministério de Meio Ambiente, vol. I, 2006. BRASIL. Resolução do CNRH no 145, de 12 de dezembro de 2012. Estabelece diretrizes para a elaboração de Planos de Recursos Hídricos de Bacias Hidrográficas e dá outras providências. Brasil, Brasília, 12 de dezembro de 2012.

BUSTOS, M. R. L. A Educação Ambiental sob a ótica da Gestão de Recursos Hídricos. Tese (Doutorado acadêmico). São Paulo: Universidade de São Paulo, 194 p, 2003.

CABRAL, A. L. A. Análise dos instrumentos da Política Nacional de Recursos Hídricos no estado de Minas Gerais. Dissertação (mestrado acadêmico). Lavras: Universidade Federal de Lavras, 113 p, 2015.

CAMPOS, L. M. S.; MELO, D. A. Indicadores de desempenho dos Sistemas de Gestão Ambiental (SGA): uma pesquisa teórica. Produção, v. 18, n. 3, 540-555 p, 2008

DA SILVA FILHO, J. C. L; SÁ DE ABREU, M. C.; KÜCHLER, J. Participação, Integração e Paradigmas como Variáveis de Análise da Gestão Ambiental Regional Através dos Comitês de Gerenciamento de Bacias Hidrográficas. Revista Eletrônica de Administração. Volume 15, n. 2, 2013, 504-530p.
GRABHER, C; BROCHI, D. F.; LAHÓZ, F. C. C. Multiplicando os Conhecimentos para a Gestão das Águas, Educação Ambiental voltada à Gestão dos Recursos Hídricos. Adaptação do livro: A Gestão dos Recursos Hídricos - buscando o caminho para as soluções, 2010, 42 p.

INSTITUTO BRASILEIRO DE GEOGRAFIA E ESTATÍSTICA - IBGE. Área Territorial Brasileira. Rio de Janeiro: IBGE, Coordenação de População e Indicadores Sociais, 2017.

INSTITUTO MINEIRO DE GESTÃO DAS ÁGUAS - IGAM. Portal dos Comitês de Bacia Hidrográfica de Minas Gerais. Belo Horizonte: IGAM, 2018. Disponível em:

<http://comites.igam.mg.gov.br/comites-estaduaismg/>. Acesso em: 10 jul. 2017.

\section{INSTITUTO MINEIRO DE GESTÃO DAS ÁGUAS}

- IGAM. Plano Estadual de Recursos Hídricos PERH. Resumo Executivo. Belo Horizonte: IGAM, 2011, 139p.

INSTITUTO MINEIRO DE GESTÃO DAS ÁGUAS - IGAM. $1^{\circ}$ Relatório anual de gestão e situação dos recursos hídricos de Minas Gerais - 2012. Belo Horizonte: IGAM, 2013. 274 p.

MINAS GERAIS. Decreto Estadual no 41.578, de 08 de março de 2001. Regulamenta a Lei $n^{\circ} 13.199$, de 29 de janeiro de 1999, que dispõe sobre Política Estadual de Recursos Hídricos. Minas Gerias, Belo Horizonte, 08 de março de 2001.

MINAS GERAIS. Decreto Estadual 44.046, de 13 de junho de 2005. Regulamenta a cobrança pelo uso de recursos hídricos de domínio do Estado. Minas Gerais, Belo Horizonte, 13 de junho de 2005.

MINAS GERAIS. Deliberação Normativa CERH n ${ }^{\mathbf{0}}$ 54, de 9 de maio de 2017. Dispõe sobre critérios e diretrizes gerais para a elaboração dos Planos Diretores de Recursos Hídricos de Bacias Hidrográficas, bem como mecanismos e critérios de acompanhamento de sua implantação e dá outras providências. Minas Gerais, Belo Horizonte, 9 de maio de 2017.

MINAS GERAIS. Deliberação Normativa CERHMG $\mathbf{n}^{\circ}$ 260, de 26 de novembro de 2010. Aprova o Plano Estadual de Recursos Hídricos do Estado de Minas Gerais. Minas Gerais, Belo Horizonte, 26 de novembro de 2010.

MINAS GERAIS. Lei no 13.199 de 29 de janeiro de 1999. Dispõe sobre a Política Estadual de Recursos Hídricos e dá outras providências. Minas Gerais, Belo Horizonte, 29 de janeiro de 1999. 
MINISTÉRIO DO MEIO AMBIENTE - MMA. Plano Nacional de Recursos Hídricos. Panorama e estado dos recursos hídricos do Brasil: Volume 1. Brasília: MMA, Secretaria de Recursos Hídricos, 2006, 153p.

MOTA, A. O. Proposição Metodológica Para Avaliação da Implementação de Planos Diretores de Recursos Hídricos. 2018. 223f. Dissertação (Mestrado em Saneamento, Meio Ambiente e Recursos Hídricos) - Escola de Engenharia, Universidade Federal de Minas Gerais, Belo Horizonte.

SANTOS, N. A. P; COSTA, P. G; FERREIRA, S. S; MOTA, A. O; MELO, M. C. Implementação dos Instrumentos de Gestão: Desafios para o Aprimoramento. In: CORREIA, C. M. C; MELO, M. C; SANTOS, N. A. P. Compartilhando Experiências das Águas de Minas Gerais - Brasil. 1.ed. Belo Horizonte: Instituto Mineiro de Gestão das Águas, 2018. p.35-40.

SENRA, J. B., NASCIMENTO, N. O. Após 20 anos da lei das águas como anda a Gestão Integrada de Recursos Hídricos do Brasil, no âmbito das Políticas e Planos Nacionais setoriais? REGA, v. 14, e6, 2017.

\footnotetext{
Allan de Oliveira Mota

Biólogo, mestre em Saneamento, Meio Ambiente e Recursos Hídricos, Analista Ambiental do Instituto Mineiro de Gestão de Águas.
}

\footnotetext{
Marília Carvalho de Melo

Engenheira Civil, doutora em Recursos Hídricos, Analista Ambiental e Diretora Geral do Instituto Mineiro de Gestão de Águas.
} 